\title{
Effect of a multi-citrus extract-based feed additive on the survival of rainbow trout (Oncorhynchus mykiss) following challenge with Lactococcus garvieae
}

\author{
Brenda Mora-Sánchez ${ }^{1,2}$, Héctor Fuertes ${ }^{1}$, José Luis Balcázar ${ }^{3,4^{*}}$ (iD and Tania Pérez-Sánchez ${ }^{1}$
}

\begin{abstract}
Growing global concerns about antibiotic resistance have generated a considerable interest in the search for alternative environmental-friendly approaches. This study was aimed to assess the antimicrobial activity of a multi-citrus extract-based feed additive (Biocitro ${ }^{\circledR}$ ) against some fish pathogens, as well as evaluate its capacity to protect rainbow trout (Oncorhynchus mykiss) to lactococcosis. A broth dilution method was used to determine the minimum inhibitory concentration (MIC) of Biocitro ${ }^{\circledR}$, and the results showed a strong antibacterial activity against Aeromonas salmonicida, Lactococcus garvieae and Yersinia ruckeri with MIC values of $2.0 \mu \mathrm{g} / \mathrm{mL}$. Afterwards, rainbow trout juveniles were fed a Biocitro ${ }^{\circledR}$-enriched diet $(750 \mathrm{mg} / \mathrm{kg}$ feed) at a daily rate of $1.5 \%$ body weight for 4 weeks, then they were challenged with L. garvieae by the cohabitation method. At the end of the experimental period, fish treated with Biocitro ${ }^{\circledR}$ showed significantly $(P<0.001)$ improved protection against L. garvieae compared to control fish. Although further studies are needed to understand how Biocitro ${ }^{\circledR}$ increases rainbow trout resistance to L. garvieae, this feed additive could be considered as a useful alternative to chemotherapeutic treatment in aquaculture.
\end{abstract}

Keywords: Antibacterial activity, Biocitro ${ }^{\circledR}$, Feed additive, Fish bacterial pathogens, Rainbow trout

\section{Findings}

Growing global concerns about antibiotic resistance and limited efficacy of vaccination have prompted the search for alternative environmental-friendly approaches in aquaculture [1]. The use of plant-derived natural compounds (phytobiotics) is gaining a considerable interest as an alternative to antibiotics, which should be restricted to prevent the emergence and spread of antibiotic-resistant bacteria [1-3]. Biocitro ${ }^{\circledR}$ (Quinabra; São José dos Campos, SP, Brazil) is a commercially available natural feed additive specifically designed for animal use. According to the manufacturer's specification, the product contains

\footnotetext{
*Correspondence: jlbalcazar@icra.cat

${ }^{3}$ Catalan Institute for Water Research (ICRA), Girona 17003, Spain

Full list of author information is available at the end of the article
}

a defined blend of citrus extracts including grapefruit (Citrus paradisi), tangerine (Citrus reticulata), bergamot (Citrus aurantium ssp. bergamia), and sweet orange (Citrus sinensis), whose active compounds are ascorbic acid, citrus bioflavonoids (hesperidin, naringin, quercetin and rutin), and organic acids [4]. The aim of this study was to evaluate the antimicrobial activity of Biocitro ${ }^{\circledR}$ against some fish pathogens, as well as investigate its capacity to protect rainbow trout (Oncorhynchus mykiss) to Lactococcus garvieae infection.

The pathogens Aeromonas salmonicida (strain CLFP 30), L. garvieae (strain CLFP 33) and Yersinia ruckeri (strain C4R7), previously isolated from rainbow trout during natural outbreaks and identified by standard microbiological methods, were grown on tryptic soy agar (TSA; Oxoid, Basingstoke, UK) overnight at $22 \pm 2{ }^{\circ} \mathrm{C}$. Afterwards, bacteria were collected and resuspended in 
phosphate-buffered saline (PBS; pH 7.4). Bacterial suspensions were spectrophotometrically adjusted to an absorbance $(600 \mathrm{~nm})$ of $0.125 \pm 0.05$, that corresponded to a reference concentration of $10^{7} \mathrm{CFU} / \mathrm{mL}$. Serial dilutions of each bacterial suspension were spread onto TSA duplicate plates and the number of colony-forming units (CFUs) was counted after incubation at $22 \pm 2{ }^{\circ} \mathrm{C}$, in order to verify the bacterial inoculum concentration. A broth dilution method was then used to determine the minimum inhibitory concentration (MIC) of Biocitro ${ }^{\circledR}$ against the three pathogens, according to Clinical and Laboratory Standards Institute guidelines [5]. Briefly, a volume of $1.0 \mathrm{~mL}$ of Biocitro ${ }^{\circledR}$, previously filtered, was added to sterile test tubes containing $1.0 \mathrm{~mL}$ of tryptic soy broth (TSB) and was serially two-fold diluted to obtain concentrations ranging from 0.25 to $250 \mu \mathrm{g} / \mathrm{mL}$. The test tubes were then inoculated with $1.0 \mathrm{~mL}$ of fresh bacterial cultures at a final concentration of $10^{5} \mathrm{CFU} /$ $\mathrm{mL}$. All assays were carried out in triplicate, including also a negative control (with medium only) and a positive control (with the reference antibiotic, oxytetracycline). Moreover, tubes containing bacteria in TSB without any other substance were used to verify bacterial growth whereas a tube containing only TSB without bacteria was used to check medium sterility during the experiments. After $24 \mathrm{~h}$ incubation at $22 \pm 2{ }^{\circ} \mathrm{C}$, bacterial growth was examined by observing the turbidity of tubes. An absence of turbidity was interpreted as absence of growth whereas the presence of turbidity was interpreted as positive growth. The MIC was defined as the lowest concentration $(\mu \mathrm{g} / \mathrm{mL})$ of Biocitro ${ }^{\circledR}$ or antibiotic that completely inhibited the visible growth of all the three bacterial species, when compared with the TSB control [6]. The results showed that $3.9,7.8$ and $7.8 \mu \mathrm{g} / \mathrm{mL}$ of oxytetracycline inhibited the growth of $A$. salmonicida strain CLFP 30, L. garvieae strain CLFP 33 and Y. ruckeri strain C4R7, respectively. Similar MIC values have been previously reported against other strains of these bacterial species isolated from farmed fish, shrimp, and their surrounding environment (water and sediment) [7-9]. The results also revealed that $2.0 \mu \mathrm{g} / \mathrm{mL}$ of Biocitro ${ }^{\circledR}$ was enough for inhibiting all tested strains. Other authors have previously shown that citrus extracts possess a strong inhibitory activity against yeasts (Saccharomyces bayanus, Pichia membranifaciens and Rhodotorula bacarum) and bacteria (Brachyspira hyodysenteriae, Lactobacillus plantarum, Lactobacillus brevis and Bacillus coagulans) [4, $10]$, thus supporting our results.

To evaluate whether Biocitro ${ }^{\circledR}$ confers to fish beneficial effects against bacterial infections, rainbow trout juveniles were fed a diet supplemented with Biocitro ${ }^{\circledR}$ for 4 weeks and then they were challenged with L. garvieae. Briefly, a total of 100 pathogen-free rainbow trout were obtained from a commercial fish farm (Viveros del Soto Oliván) in the Autonomous Community of Aragon, Spain. After an acclimatization period of 2 weeks, fish (mean body weight $25.0 \pm 5.0 \mathrm{~g}$ ) were randomly assigned to three experimental groups and maintained in three tanks. Specifically, two groups were fed a commercial feed (Inicio Plus 887; BioMar Iberia, S.A., Dueñas, Spain) without any supplement: one group $(n=40)$ was used as untreated control and submitted to infection, whereas the other group $(n=20)$ was used for the experimental infection as donors. The third group $(n=40)$ received a diet obtained by adding Biocitro ${ }^{\circledR}$ to the commercial diet at $750 \mathrm{mg} / \mathrm{kg}$ and then was infected. Water quality parameters were measured daily, and temperature $\left(17.0 \pm 0.8^{\circ} \mathrm{C}\right)$, dissolved oxygen $(6.7 \pm 0.5 \mathrm{mg} / \mathrm{L})$, $\mathrm{pH}(6.9 \pm 0.2)$, nitrite $(0.03 \pm 0.01 \mathrm{mg} / \mathrm{L})$, and nitrate $(0.8 \pm 0.2 \mathrm{mg} / \mathrm{L})$ were constant throughout the experiment. All fish were maintained in aerated fresh water with a $25 \%$ water change every day and a $12 \mathrm{~h}$ dark/12 h light photoperiod, and they were fed daily at $1.5 \%$ of their biomass. After 4 weeks of feeding, fish were individually weighed to evaluate the effect of Biocitro ${ }^{\circledR}$ on growth. Subsequently, fish were challenged with L. garvieae by cohabitation method [11, 12]. L. garvieae cells, previously grown on TSA plates, were collected and resuspended in PBS. Bacterial concentration was spectrophotometrically adjusted to $10^{4} \mathrm{CFU} /$ $\mathrm{mL}$, and serial dilutions were spread onto TSA plates to verify the infective dose. A volume of $0.1 \mathrm{~mL}$ was intraperitoneally injected into donors, which were previously anaesthetized with tricaine methanesulphonate (Tricaine Pharmaq $1000 \mathrm{mg} / \mathrm{g}$ ) and marked by clipping the adipose fin. Then, ten infected fish were transferred into the tanks containing the other two experimental groups. All fish were monitored at least three times daily for 2 weeks, and dead fish were immediately removed and examined for external signs of lactococcosis, such as lethargy, irregular swimming behavior, exophthalmia and hemorrhages in the periorbital and intraocular area, perianal region and base of fins. Necropsy results indicated different severity of internal lesions, including enlarged spleen, extensive hemorrhages and ascites.

At the end of the experimental period, fish growth data were analyzed using unpaired two-tailed Student's $t$ test. Kaplan-Meier survival analysis was performed to investigate statistical differences among the experimental groups $(\mathrm{P}<0.05)$. Statistical analyses were performed using $R$ version 3.4.3 (R Foundation for Statistical Computing, Vienna, Austria). No significant difference $(P=0.30)$ was observed in the final weight between fish fed the Biocitro ${ }^{\circledR}$-enriched diet and control group (Fig. 1). Moreover, no side effects associated with its use was observed. However, a significant difference $(P<0.001)$ in the cumulative survival between 


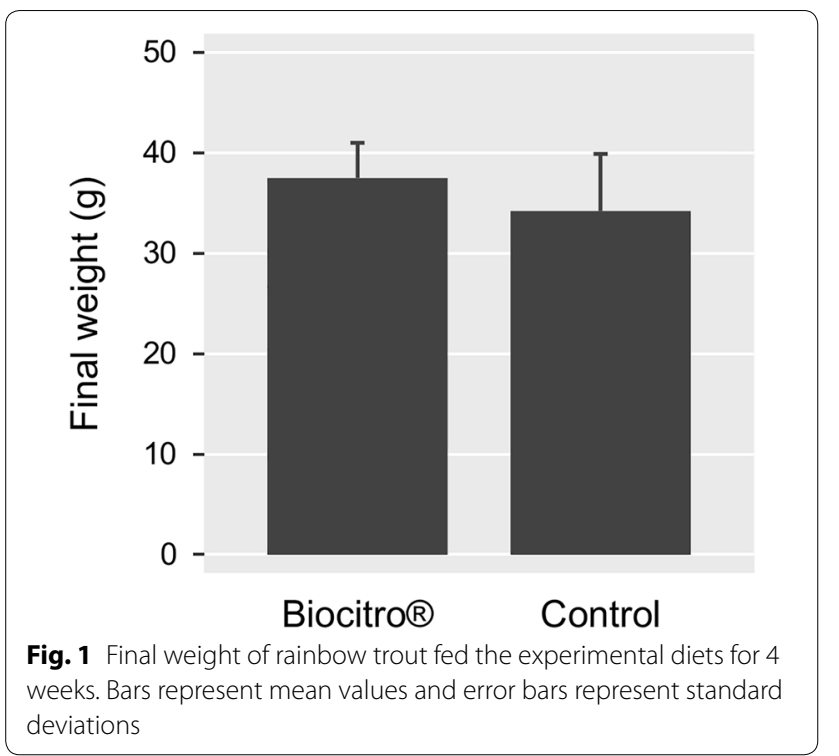

fish fed a Biocitro ${ }^{\circledR}$-enriched diet and control group was recorded (Fig. 2). Cumulative survivals were $82.5 \%$ (95\% CI 71.5-95.2\%) and 37.5\% (95\% CI 25.1-55.9\%) in treated and control groups, respectively. The relative percent survival (RPS) of treated fish was $72 \%$, calculated as previously described [13]. These results seem to be consistent with previous studies, which revealed that the administration of phytobiotics in fish confers protection against bacterial infections. For instance, another commercially available phytogenic feed additive (Digestarom ${ }^{\circledR}$ ) conferred protection against A. salmonicida to rainbow trout [14], and its dietary supplementation resulted also correlated with a statistically significant reduction of mortality in channel catfish (Ictalurus punctatus) challenged with Edwardsiella ictaluri [15]. These evidences suggest a direct antimicrobial activity of Digestarom ${ }^{\circledR}$ that can be ascribable to its active compounds including anethole, carvacrol, limonene and thymol [14, 15]. However, other authors reported that these substances can modulate the immune responses and intestinal microbiota in rainbow trout [16]. Moreover, the inclusion of PHYTO $^{\circledR}$ in the diet reduced the susceptibility of European sea bass (Dicentrarchus labrax) to Vibrio anguillarum [17], which could be related to the antibacterial properties of its active compounds from garlic and labiatae plant extracts.

In conclusion, this study highlighted that Biocitro ${ }^{\circledR}$ could be proposed as alternative to antibiotics for the treatment of fish diseases, being effective in increasing rainbow trout survival to lactococcosis probably by a direct antibacterial activity when administered as feed additive. However, further studies are needed to elucidate the exact mechanisms of its action and investigate whether Biocitro ${ }^{\circledR}$ is also capable to enhance the immune response and/or induces changes in fish intestinal microbiota.

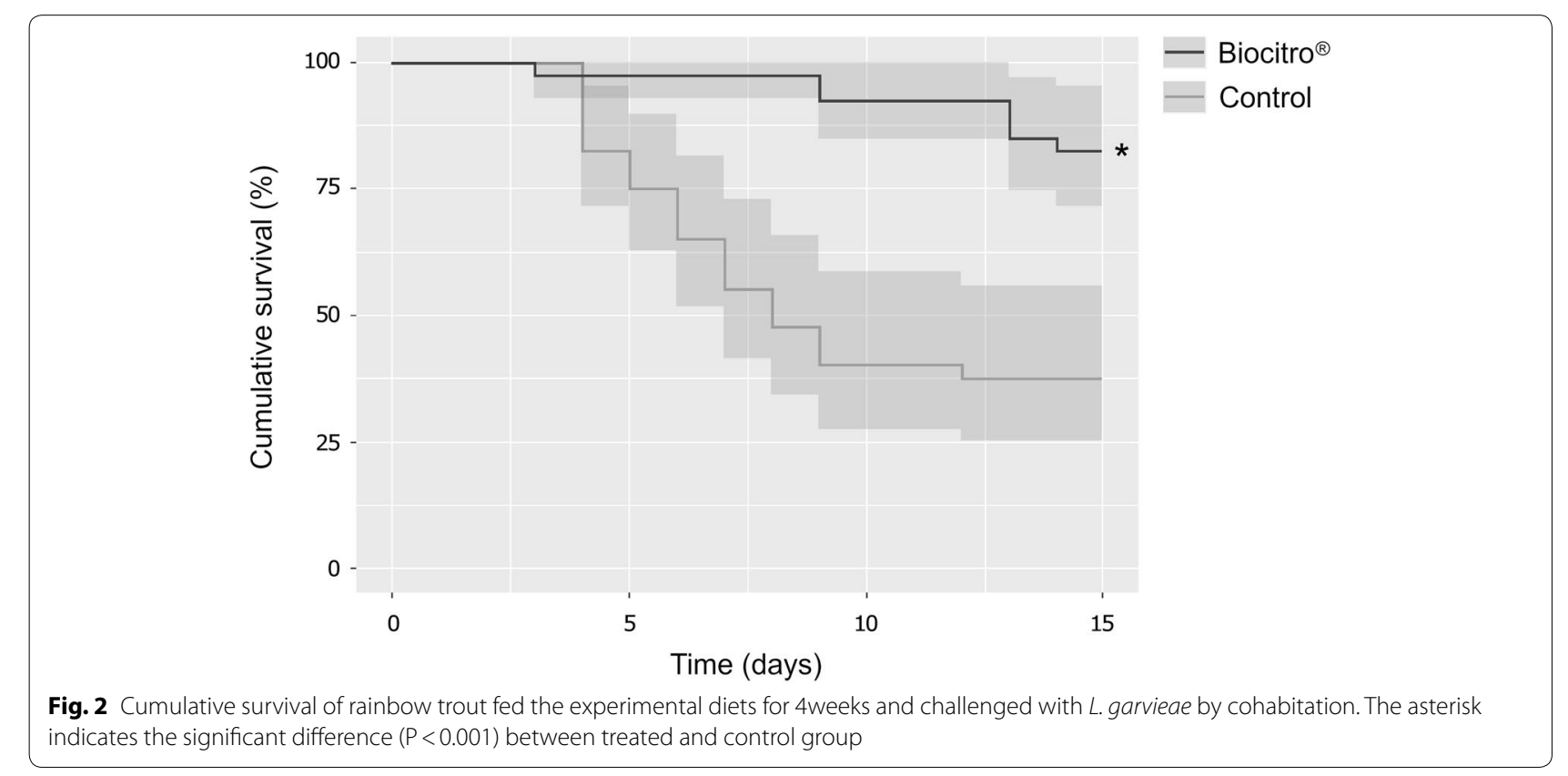




\section{Acknowledgements}

B. Mora-Sánchez was supported by a fellowship from "Banco Santander Universidad de Zaragoza". ICRA is part of the CERCA Programme of the Catalan Government.

\section{Authors' contributions}

TPS and JLB designed the experiments; TPS and BMS performed the experiments; HF and BMS analyzed and interpreted the data; TPS and JLB wrote the paper. All authors read and approved the final manuscript.

\section{Funding}

This research did not receive any specific grant from funding agencies in the public, commercial, or not-for-profit sectors.

\section{Availability of data and materials}

The datasets used and/or analyzed during the current study are available from the corresponding author on reasonable request.

\section{Ethics approval and consent to participate}

The study was conducted considering the 3 Rs principle (reduction, replacement and refinement). The care and use of fish were performed accordingly with the Spanish Policy for Animal Protection RD53/2013, which meets the European Union Directive 2010/63 on the protection of animals used for experimental and other scientific purposes.

\section{Consent for publication}

Not applicable.

\section{Competing interests}

The authors declare that they have no competing interests.

\section{Author details}

1 Department of Animal Pathology, Faculty of Veterinary Sciences, Universidad de Zaragoza, Saragossa 50013, Spain. ${ }^{2}$ Department of Animal Health, Centro Veterinario de Diagnóstico e Investigación (CEVEDI), School of Veterinary Medicine, Universidad Nacional Autónoma de Nicaragua-León, León, Nicaragua.

${ }^{3}$ Catalan Institute for Water Research (ICRA), Girona 17003, Spain. ${ }^{4}$ University of Girona, Girona 17004, Spain.

Received: 6 March 2020 Accepted: 26 June 2020

Published online: 01 July 2020

\section{References}

1. Pérez-Sánchez T, Mora-Sánchez B, Balcázar JL. Biological approaches for disease control in aquaculture: advantages, limitations and challenges. Trends Microbiol. 2018;26:896-903.

2. Kareem ZH, Abdelhadi YM, Christianus A, Karim M, Romano N. Effects of some dietary crude plant extracts on the growth and gonadal maturity of Nile tilapia (Oreochromis niloticus) and their resistance to Streptococcus agalactiae infection. Fish Physiol Biochem. 2016;42:757-69.

3. Yang C, Chowdhury MA, Huo Y, Gong J. Phytogenic compounds as alternatives to in-feed antibiotics: Potentials and challenges in application. Pathogens. 2015;4:137-56.
4. de Nova PJ, Carvajal A, Prieto M, Rubio P. In vitro susceptibility of Brachyspira hyodysenteriae to a commercial citrus fruit extract. Res Vet Sci. 2017;115:318-24.

5. CLSI. Methods for dilution antimicrobial susceptibility tests for bacteria that grow aerobically, approved standard, 9th ed., CLSI document M07A9. Wayne, PA: Clinical and Laboratory Standards Institute; 2012.

6. Lorian $\mathrm{V}$, Atkinson BA. Determination of the range of antibacterial activity by use of viable counts. J Clin Microbiol. 1982;16:70-6.

7. Schmidt AS, Bruun MS, Dalsgaard I, Pedersen K, Larsen JL. Occurrence of antimicrobial resistance in fish-pathogenic and environmental bacteria associated with four Danish rainbow trout farms. Appl Environ Microbiol. 2000;66:4908-15.

8. Kawanishi M, Kojima A, Ishihara K, Esaki H, Kijima M, Takahashi T, Suzuki S, Tamura Y. Drug resistance and pulsed-field gel electrophoresis patterns of Lactococcus garvieae isolates from cultured Seriola (yellowtail, amberjack and kingfish) in Japan. Lett Appl Microbiol. 2005;40:322-8.

9. Rodgers CJ. Resistance of Yersinia ruckeri to antimicrobial agents in vitro. Aquaculture. 2001;196:325-45.

10. Bevilacqua A, Corbo MR, Sinigaglia M. In vitro evaluation of the antimicrobial activity of eugenol, limonene, and citrus extract against bacteria and yeasts, representative of the spoiling microflora of fruit juices. J Food Prot. 2010;73:888-94.

11. Vendrell D, Balcázar JL, de Blas I, Ruiz-Zarzuela I, Gironés O, Múzquiz JL. Protection of rainbow trout (Oncorhynchus mykiss) from lactococcosis by probiotic bacteria. Comp Immunol Microbiol Infect Dis. 2008;31:337-45.

12. Pérez-Sánchez T, Mora-Sánchez B, Vargas A, Balcázar JL. Changes in intestinal microbiota and disease resistance following dietary postbiotic supplementation in rainbow trout (Oncorhynchus mykiss). Microb Pathog. 2020;142:104060

13. Amend DF. Potency testing of fish vaccines. In: Hennessen, W. (Ed.), Fish Biologics: Serodiagnostics and Vaccines. Dev Biol Stand. 1981;49:447-54

14. Menanteau-Ledouble S, Krauss I, Santos G, Fibi S, Weber B, El-Matbouli M. Effect of a phytogenic feed additive on the susceptibility of Oncorhynchus mykiss to Aeromonas salmonicida. Dis Aquat Org. 2015;115:57-66.

15. Peterson BC, Peatman E, Ourth DD, Waldbieser GC. Phytogenic feedadditive effects on channel catfish rhamnose-binding lectin levels, and susceptibility to Edwardsiella ictaluri. Dis Aquat Org. 2018;129:99-106.

16. Giannenas I, Triantafillou E, Stavrakakis S, Margaroni M, Mavridis S, Steiner $\mathrm{T}$, et al. Assessment of dietary supplementation with carvacrol or thymol containing feed additives on performance, intestinal microbiota and antioxidant status of rainbow trout (Oncorhynchus mykiss). Aquaculture. 2012;350-353:26-32.

17. Torrecillas S, Terova G, Makol A, Serradell A, Valdenegro V, Gini E, et al. Dietary phytogenics and galactomannan oligosaccharides in low fish meal and fish oil-based diets for European sea bass (Dicentrarchus labrax) juveniles: Effects on gut health and implications on in vivo gut bacterial translocation. PLoS ONE. 2019;14:e0222063.

\section{Publisher's Note}

Springer Nature remains neutral with regard to jurisdictional claims in published maps and institutional affiliations.

Ready to submit your research? Choose BMC and benefit from:

- fast, convenient online submission

- thorough peer review by experienced researchers in your field

- rapid publication on acceptance

- support for research data, including large and complex data types

- gold Open Access which fosters wider collaboration and increased citations

- maximum visibility for your research: over $100 \mathrm{M}$ website views per year

At BMC, research is always in progress.

Learn more biomedcentral.com/submissions 